\title{
Squeeze casting of electromagnetically stirred aluminum matrix nanocomposites in semi-solid condition using hybrid algorithm optimized parameters
}

\author{
M. Shamsipour ${ }^{1 *}$, Z. Pahlevani ${ }^{1}$, M. O. Shabani ${ }^{2}$, A. Mazahery ${ }^{3,4}$ \\ ${ }^{1}$ Department of Mechanical Engineering, Faculty of Engineering, Najafabad Branch, Islamic Azad University, Najafabad, \\ Isfahan, Iran \\ ${ }^{2}$ Iran University of Industries and Mines (IUIM), Tehran, Iran \\ ${ }^{3}$ Leichtmetallkompetenzzentrum LKR, Austrian Institute of Technology, Austria \\ ${ }^{4}$ Department of Mechanical Engineering, McMaster University, Ontario, Canada
}

Received 3 November 2015, received in revised form 2 March 2016, accepted 9 March 2016

\begin{abstract}
The government mandated fuel efficiency standards for automobile manufacturers reinforce the incentives to reduce the fuel consumption of their vehicles and minimize $\mathrm{CO}_{2}$ greenhouse emission, which requires developing the lighter vehicles, while preserving product performance and cost objectives. One of the effective means to address this challenge has been the design and application of lightweight materials including AMNCs for the automotive parts. Multiple methods have been introduced to manufacture AMNCs such as compocasting in which the reinforcement particles are added to a solidifying melt while being agitated by the electromagnetic field in EMS apparatus. The slurry is then poured into the die cavity and squeezed during the solidification.

This research employs ANFIS-PSO in order to optimize the parameters in compocast processing of AMNCs. The objective function is calculated and minimized by ANFIS and PSO, respectively. The optimized electromagnetic stirring process was used to produce the AMNCs with superior wear resistance.
\end{abstract}

K e y words: compocasting, AMNCs, electromagnetic, nanocomposites

\section{Introduction}

Automotive industry requires materials with low density, excellent mechanical properties, and high wear resistance [1-4]. Aluminum alloys are popular, but prove to be relatively soft for many applications and therefore do not meet all the requirements for tribological purposes [5-7]. In general, composites are the materials manufactured by adding two or more materials which are in physically and/or chemically distinct phases [8, 9]. Ceramic particles including TiC, $\mathrm{SiC}, \mathrm{B}_{4} \mathrm{C}, \mathrm{Al}_{2} \mathrm{O}_{3}, \mathrm{Mg}_{2} \mathrm{Si}$, etc. $[10-12]$ in micron sizes are added to the aluminum in order to improve its wear resistance, while particles in nano size enable enhancement in both mechanical and tribological properties [13]. Aluminum matrix nanocomposites (AM$\mathrm{NCs}$ ) are used where the application requires high tensile strength, hardness, toughness including pistons and cylinder liners, brake drums and discs [14-18]. There are various methods to manufacture $\mathrm{Al}$ matrix composites such as powder metallurgy, electroplating and electroforming, stir casting, pressure infiltration, squeeze casting, spray deposition, semi-solid powder processing, etc. Compocasting is a method in which the reinforcement particles are added to a solidifying melt while being agitated [19-22]. The primary solid particles formed in the semi-solid slurry reduce agglomeration of the reinforcing particles. This will result in better distribution of the reinforcement particles and a globular structure. It is now being reviewed as one of the manufacturing methods of composite materials due to its superior advantage over a forming process. Agitation can be made by mechanical vibration, mechanical stirring, electromagnetic stirring

*Corresponding author: tel.: +98 912563 6709; fax: +98 261 6201888; e-mail adresses: majid60shamsipour@gmail.com, shamsipour@iaun.ac.ir 
(EMS) and cooling slope techniques. Electromagnetic stirring is one of the common ways to create globular structure in metals. In this method, the desired metal is stirred in the range of semi-solid temperature by rotating Lorentz force resulted from the magnetic field of coils and consequently the dendritic cast structure is transformed into a globular structure [16, 23-26]. Shabani et al. [25] showed that the globular structure of the alloy is affected by the parameters such as intensity of magnetic stirring and cooling rate. Different aluminum alloys have been used as the matrix. Al-Si alloy is the materials choice for compocasting via EMS due to its good castability and ability to generate a semi-solid alloy structure without cavities and defects. The structure of the cast alloy contains primary $\alpha-\mathrm{Al}$ dendritic phase and eutectic regions containing Si particles in the $\alpha$-Al matrix. Mechanical properties of this alloy are determined by the shape, size and distribution of Si particles [23-25].

Theory of particle swarm optimization (PSO) has attracted many attentions in last few years [27]. The PSO algorithm is similar to how societies of animals with no leader behave. Typical examples are bird flocking and fish schooling where animals go after a member of the group with the closest position to the target (potential solution). The groups reach their best condition simultaneously through communication among members who already have a better situation [28-32]. The ones with a better condition supervise the flocks, and the rest follow them simultaneously to that place. This repeatedly occurs until the best conditions or source of a food are discovered. The process of PSO algorithm in finding optimal values follows the work of this animal society. Particle swarm optimization consists of a swarm of particles, where particle represents a potential solution [33-35].

A neural network is a nonlinear dynamic computational system where, rather than relying on a number of predetermined assumptions, data is used to form the model [36-40]. Neural networks have traditionally been viewed as simplified models of neural processing in the human brain [41-43]. Adaptive neurofuzzy inference system (ANFIS) belongs to the class of adaptive networks, which are functionally equivalent to fuzzy inference systems (FIS). The FIS is a conventional computing framework in accordance with the concepts of fuzzy set theory, fuzzy if-then rules, and fuzzy reasoning. The ANFIS enables simulation and analysis of the correlation between the input and output data through a hybrid learning to find optimal parameters of a given FIS [44-46]. It is trained without the expert knowledge, which is usually needed for the standard fuzzy logic design. The main advantage of the ANFIS is that ANFIS totally bypasses the repeated application of complex iterative processes for new cases presented to it. Although a few minutes are required for the training, it takes only a few microsec- onds for the test to be completed. Because of these attractive features, ANFIS has been applied to many areas in the literature $[44,46]$.

Study of literature shows no previous attempt in using an electromagnetic stirrer device to obtain a uniform distribution of the particles. It is of interest to optimize the possessing in an attempt to obtain a high wear resistant nanocomposite with a stable tribolayer on the wearing surface and fine equiaxed wear debris. Finally, the wear behavior of optimized processed composites is evaluated.

An investigation is carried out on the influence of applied load, sliding speed, wearing surface, hardness, reinforcement fracture toughness, and morphology as the critical parameters in relation to the wear regime.

\section{Experimental}

The Al-Si alloy (chemical composition: $7 \% \mathrm{Si}$, $0.3 \% \mathrm{Mg}, 0.3 \% \mathrm{Zn}, 0.3 \% \mathrm{Cu}, 0.3 \% \mathrm{Fe}$ and the rest $\mathrm{Al}$ ) and $\mathrm{TiC}$ nanoparticles have been selected as the matrix and the reinforcement, respectively. It has been evident that small size of particles results in their high tendency for agglomeration at various stages during processing. This problem is expected to pose a major obstacle for uniform distribution of $\mathrm{TiC}$ nanoparticles in the melt as they have large specific surface area and high interfacial energy. In order to overcome this problem, ameliorate the wettability of $\mathrm{TiC}$ nanoparticles with the melt, reduce their agglomeration, and attain a uniform distribution of $\mathrm{TiC}$ nanoparticles in the matrix, a special technique was used for introduction of nanoparticles into the melt. Nanoparticles were injected into the melt in the form of a mixture of $\mathrm{TiC}$ nanoparticles and $\mathrm{Al}$ powder. The powders were mixed and then pressed into the disc shape. The diameter and height of each disk were $10 \mathrm{~mm}$ and $3 \mathrm{~mm}$, respectively. The alloy was melted in a resistance furnace at $720^{\circ} \mathrm{C}$ and then degassed for $10 \mathrm{~min}$ with argon gas through a graphite lance. The discs were then added using an electromagnetic stirrer device to obtain a uniform distribution of the particles. The temperature was lowered to convert the liquid into a semisolid slurry. The slurry was immediately poured into the die cavity and squeezed during the solidification. The current was varied 0,50 and 100 A while voltage was kept constant and equal to $220 \mathrm{~V}$. Size and volume percentage of $\mathrm{TiC}$ nanoparticles and the casting temperature are the optimized parameters obtained using ANFIS-PSO model. Figure 1 shows the distribution of electromagnetic field in EMS apparatus. For comparison, conventional liquid sand cast samples were poured at $720^{\circ} \mathrm{C}$ without electromagnetic stirrer device treatment.

The samples are solution treated at a temperature of $545^{\circ} \mathrm{C}$ for $4 \mathrm{~h}$ and quenched in water to room tempe- 


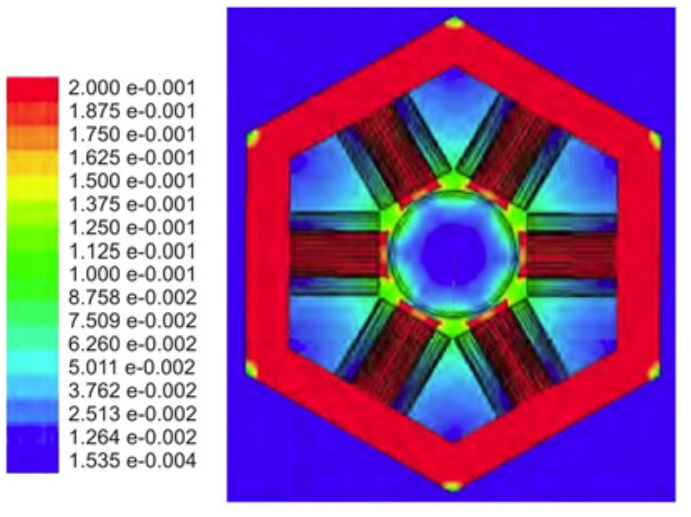

Fig. 1. Distribution of electromagnetic field in EMS apparatus.

rature. T6 heat treatment is done at $155^{\circ} \mathrm{C}$ for $6 \mathrm{~h}$ to reach the peak aging condition. Samples for the metallographic examination were cut, ground, and polished down to $0.5 \mathrm{~m}$ and etched using Keller's agent. The microstructures were observed and analyzed with an optical microscope and SEM. Hardness values of the samples were measured on the polished samples at a load of $100 \mathrm{~g}$. An image analyzer was used to measure the average diameter of the primary $\alpha$-Al particles using a mean line incept method defined as

$$
\text { Average diameter }=L / N \text {, }
$$

where $L$ is the overall length of measured series lines, $N$ is the number of particles passed through by the measured lines. This evaluation was repeated until 500 grains in several images were counted.

The shape factor of a particle in this study was defined as

$$
\text { Shape factor }=4 \pi A / P^{2} \text {, }
$$

where $A$ and $P$ represent the sectional area and the perimeter of the primary phase in the microstructure, respectively.

Dry sliding wear tests were performed using a pinon disc-type wear apparatus. The slider disc was casehardened steel with $63 \mathrm{HRC}$ to a depth of $3 \mathrm{~mm}$. The composites were formed into pin having $6 \mathrm{~mm}$ diameter and $35 \mathrm{~mm}$ height. The pins were put in contact with the slider. Both surfaces were polished to $0.5 \mathrm{~mm}$ and ultrasonically cleaned prior to testing. The tests were carried out for different sliding distances under a normal load of $20 \mathrm{~N}$. The weight losses were calculated from the differences in weight of the specimens measured before and after the tests with a precision of $\pm 0.1 \mathrm{mg}$ using an analytical balance. A separate specimen was used to measure the weight loss for each sliding distance. The wear test was interrupted at regular intervals, and the incremental weight loss of the

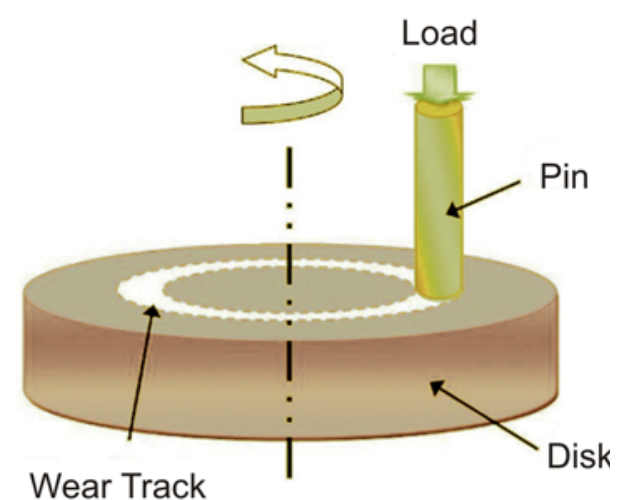

Fig. 2. Schematic diagram of the abrasion wear test.

sample was recorded. After each increment and before weighing, the disc and the pin were cleaned in an ultrasonic bath with acetone and hot wind dried below $100^{\circ} \mathrm{C}$. Figure 2 shows a schematic diagram of the abrasion wear test. The wear tests were conducted up to the total sliding distance of $2000 \mathrm{~m}$.

\section{Adaptive neuro-fuzzy inference system}

Among different fuzzy inference systems, Takagi-Sugeno (TS) system is successfully used for fuzzy modeling. An ANFIS system may be accounted as an implementation of a TS system in neural-network architecture [43, 44]. Five layers are used to form the ANFIS model, each layer with a couple of nodes described by a node function. The circles in the network represent nodes with no variable parameters, while the squares show nodes with adaptive parameters to be determined by the network during training [46]. The nodes in the first layer represent fuzzy sets in fuzzy rules. It has parameters that control the shape and the location of the center of each fuzzy set which are called premise parameters. In the second layer, every node computes the product of its inputs [46]. In Layer 3, normalization of the firing strength of the rules occurs by calculating the ratio of the $i$ th rule's firing strength to the sum of all rules firing strengths. Nodes in the fourth layer are adaptive, where each node function represents a first-order model with consequent parameters [47]. Layer 5 is called the output layer where each node is fixed. It computes the overall output as the summation of all the inputs from the previous layer. Optimizing the values of the adaptive parameters is the most important step for the performance of the adaptive system. Especially, the supposed parameters in Layer 1 and the consequent parameters in Layer 4 need to be determined. Jang proposed a hybrid learning algorithm for determining the parameters of an ANFIS model [48]. A hybrid learning 
algorithm uses the gradient descent and least-square techniques for optimizing the network parameters [44]. The least-squares estimation can be used to determine consequent parameters, assuming that the Layer 1 parameters are fixed. Then, the Layer 4 parameters can be fixed, and a back propagation approach is used to fit the premise parameters in Layer 1. Iterating between the Layer 1 parameters and the Layer 4 parameters optimization, the optimal values for all free parameters are computed.

\section{Particle swarm optimization}

The PSO algorithm was first proposed by Kennedy, inspired by the natural flocking and swarming behavior of birds and insects. The concept of PSO gained in popularity due to its simplicity. Like other swarm-based techniques, PSO consists of a number of individuals refining their knowledge of the given search space $[49,50]$. The individuals in a PSO have a position and velocity and are denoted as particles. The PSO traditionally has no crossover between individuals, has no mutation and particles are never substituted by other individuals during the run. The PSO algorithm works by attracting the particles to search space positions of high fitness [33, 34]. Each particle has a memory function and adjusts its trajectory according to two pieces of information, the best position that it has so far visited, and the global best position attained by the whole swarm [31]. If the whole swarm is considered as a society, the first piece of information can be seen as resulting from the particle's memory of its past states, and the second piece of information can be seen as resulting from the collective experience of all members of the society [21, 29, 49]. Like other optimization methods, PSO has a fitness evaluation function that takes each particle's position and assigns it a fitness value. The position of highest fitness value visited by the swarm is called the global best. Each particle remembers the global best, and the position of highest fitness value that has personally visited, which is called the local best [34].

A swarm consists of $N$ particles moving around in a $D$-dimensional search space. The $i$ th particle at the $t$ th iteration has a position $X_{i}=\left(X_{i 1}, \ldots, X_{i D}\right)$, a velocity, $V_{i}=\left(V_{i 1}, \ldots, V_{i D}\right)$, the best solution achieved so far by itself $\left(p_{\text {best }}\right) P_{i}=\left(P_{i 1}, \ldots, P_{i D}\right)$. The best solution achieved so far by the whole swarm ( $\left.g_{\text {best }}\right)$ is represented by $P_{g}=\left(V_{g 1}, \ldots, V_{g D}\right)$. The position of the $i$ th particle at the next iteration will be calculated according to the following equations $[21,29,30]$ :

$$
\begin{gathered}
V_{i d}^{t+1}=w V_{i d}^{t}+c_{1} \operatorname{rand}()\left(P_{i d}-X_{i d}^{t}\right)+ \\
+c_{2} \operatorname{rand}()\left(P_{g d}-X_{i d}^{t}\right), \\
X_{i d}^{t+1}=V_{i d}^{t+1}+X_{i d}^{t},
\end{gathered}
$$

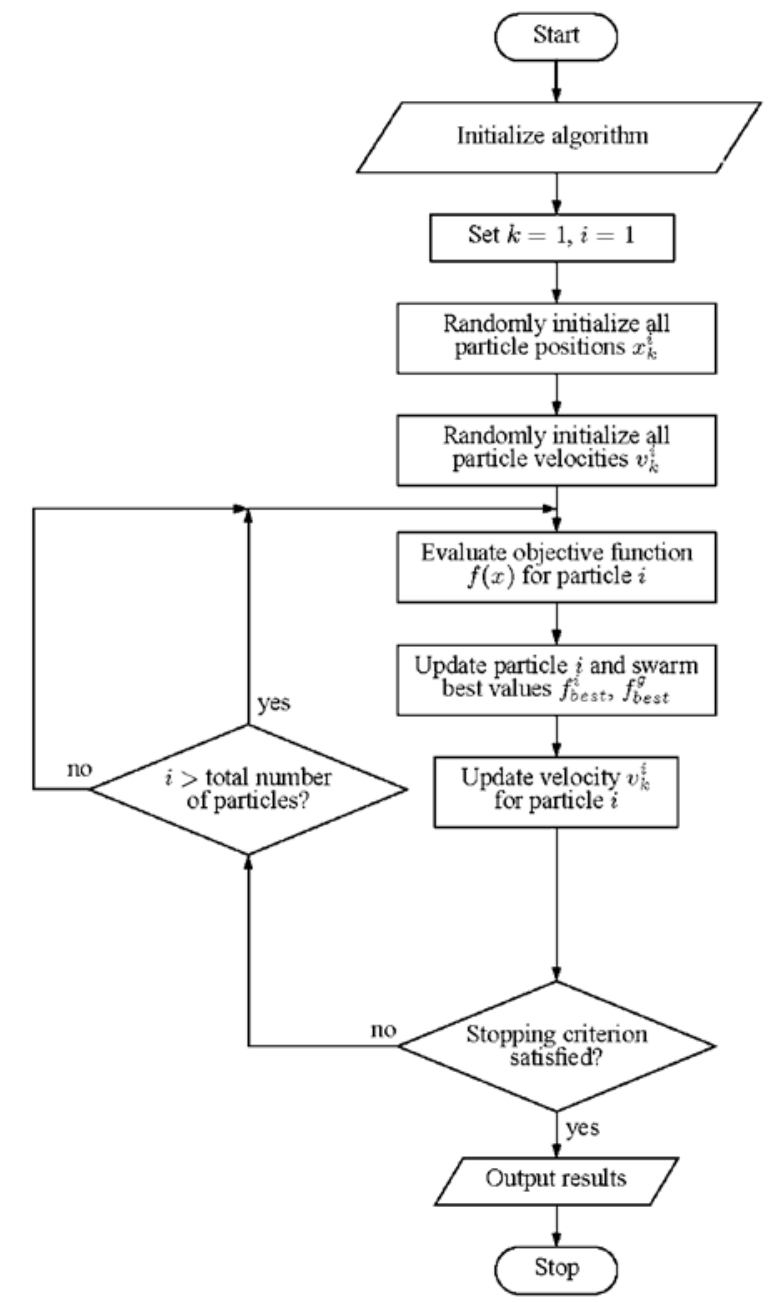

Fig. 3. The flowchart of PSO model.

where $c_{1}$ and $c_{2}$ are two positive constants, called cognitive learning rate and social learning rate, respectively; rand is a random function in the range $[0,1] ; w$ is inertia factor which linearly decreases from 0.9 to 0.4 through the search process. In addition, the velocities of the particles are confined within $\left[V_{\min }, V_{\max }\right]^{D}$. If an element of velocities exceeds the threshold $V_{\min }$ or $V_{\max }$, it is set equal to the corresponding threshold [51]. The iterative PSO approach can be described as follows:

1. Initial positions and velocities for all agents are generated. The current position of each particle is stored as $P_{i}$. The $P_{i}$ with the best value is designated as $P_{g}$, and this value is stored.

2 . The next position for each particle is generated using Eqs. (3) and (4).

3. The objective function value is calculated for the new positions of each particle. If an agent achieves a better position, its $P_{i}$ value is replaced by the current value.

4. As in step 1 , a $P_{g}$ value is selected from the new 


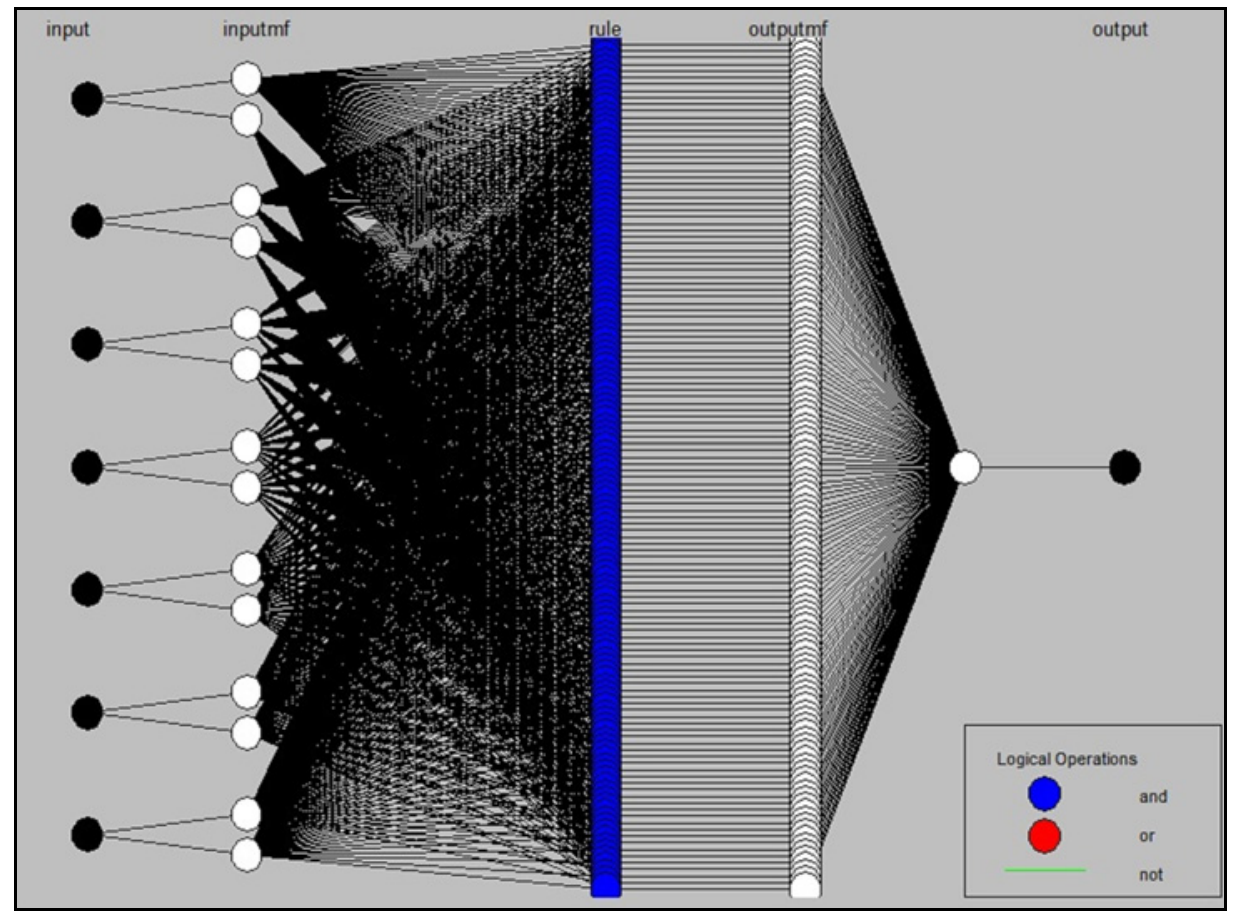

Fig. 4. The structure of the ANFIS in the present model.

set of $P_{i}$ values. If the new $P_{g}$ value is better than the previous $P_{g}$ value, the previous $P_{g}$ value is replaced by the new $P_{g}$ value.

5 . Repeat steps $2-4$ until the number of iterations reaches a predetermined value.

Figure 3 shows the flowchart of PSO model which has been used in this investigation.

\section{Optimization}

The ANFIS editor presents eight different types of membership functions for decision-makers to use in problems: Triangular, Trapezoidal, Generalized bell, Gaussian curve, Gaussian combination, P-shaped, Difference between two sigmoid functions, and Product of two sigmoid functions. The most significant step in the model is defining fuzzy membership function and corresponding value. Gaussian and bell membership functions are most popular methods for specifying the fuzzy set because of their smoothness and concise notation. Both membership functions have advantages of being smooth and non-zero at each point. The bell membership function has one more parameter than Gaussian membership function, so it can approach non-fuzzy set if the free parameter is tuned. Therefore, the Gaussian membership function has been considered. There are only two choices for the output membership function: constant and linear since ANFIS only operates on Sugeno-type systems. For the sake of performance, the constant membership function was chosen. Among samples, $70 \%$ were used for training and the remaining $30 \%$ were used for testing and validation. The samples were chosen randomly. After determining the number and type of membership functions, the ANFIS model is structured as illustrated in Fig. 4. Even though the ANN coupled with fuzzy logic seems to be useful, there exists a drawback for this hybrid model, since it imposes stringent requirements on the quality of training dataset as the learning becomes entirely data driven. The hybrid algorithm has been applied to the membership function of each input. The advantage of the hybrid method is that it uses back propagation for a parameter associated with input membership function and least square estimation for parameters associated with output membership. Each input was normalized into a range of $[0,1]$.

Consequently, the trained model might behave erratically in unseen input conditions and becomes uninterpretable in the case that the training dataset is not adequate. From this operation with ANFIS, the objective function is calculated which was then minimized by PSO. Final optimized parameters of the process are 2.3 volume percentage of $\mathrm{TiC}, 94 \mathrm{~nm}$ average particle size of $\mathrm{TiC}, 619^{\circ} \mathrm{C}$ casting temperature, $2.5 \%$ porosity, elongation percentage is $3 \%$ and $189 \mathrm{MPa}$ yield strength.

\section{Optimized experimental results}

Figure 5 shows the effect of various electromagnetic currents on the microstructure of the compocast $\mathrm{Al}$ re- 


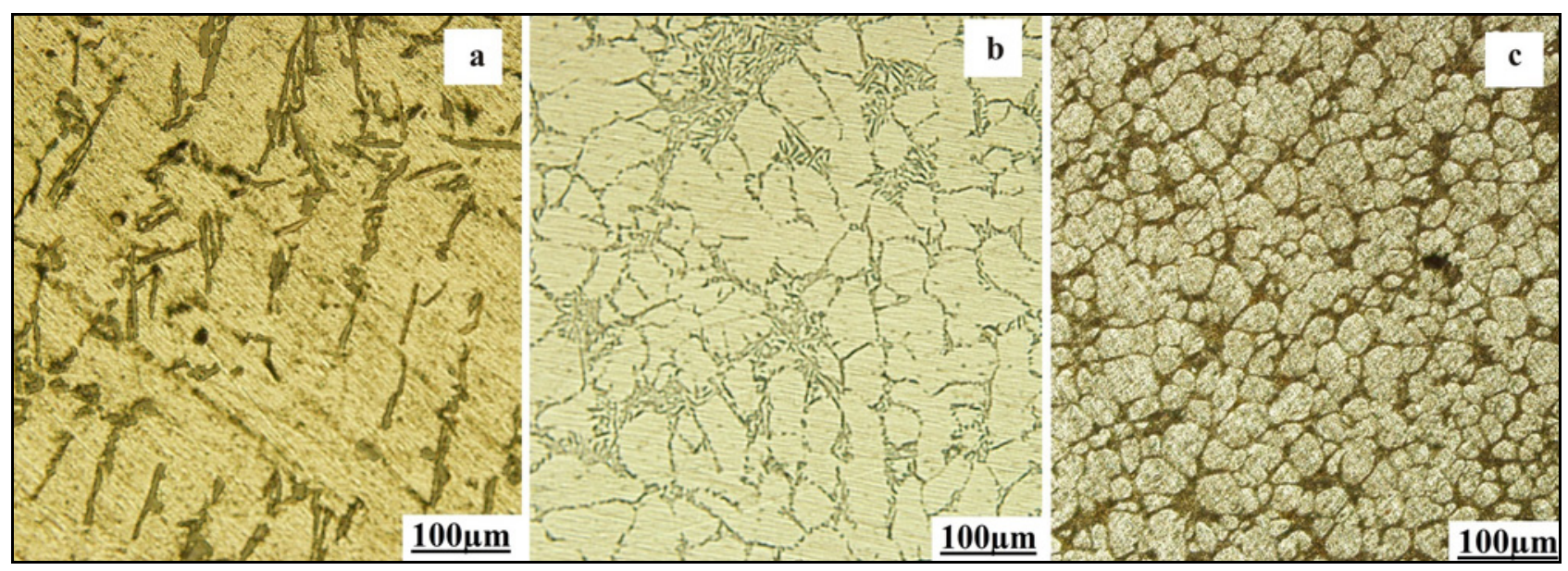

Fig. 5. Effect of various electromagnetic currents on the microstructure of the compocast $\mathrm{Al}$ reinforced with $2.3 \%$ nanoTiC: (a) conventional liquid sand cast, (b) $50 \mathrm{~A}$, (c) $100 \mathrm{~A}$.

inforced with $2.3 \%$ nano-TiC. The microstructure of this alloy contains coarse dendritic $\alpha$-Al and continuous eutectic network (Si particles and $\alpha-\mathrm{Al}$ ). Figure $5 \mathrm{a}$ shows the conventional liquid sand cast sample with dendritic primary $\alpha$-Al and coarse arms in which the electromagnetic current is not imposed. Figures $5 \mathrm{~b}, \mathrm{c}$ show the microstructure of $\mathrm{Al}$ alloy obtained at the different electromagnetic field. The maximum sphericity and medium mean diameter of the globules are obtained by $I=100 \mathrm{~A}$ (Fig. 5c). When the EMS current is $50 \mathrm{~A}$, the morphology of primary $\alpha$ - $\mathrm{Al}$ particles turned out to be coarse, while the microstructure of $\mathrm{Al}$ alloy processed at $100 \mathrm{~A}$ consists of primary $\alpha-\mathrm{Al}$ particles with globular-like fine grain size. With increasing electromagnetic current, the solid phases are ripened and therefore small eutectic areas are merged together becoming as an intergranular phase. This phenomenon increases the thickness of eutectic regions.

Figure 6 shows the average diameter and shape factor of primary phase in the semisolid $\mathrm{Al}$ alloy prepared at the different electromagnetic field. One can see that, when the electromagnetic field is not applied, the primary $\alpha-\mathrm{Al}$ phase is coarse with an average diameter of more than $77 \mu \mathrm{m}$ and a rather low shape factor of 0.21 . With the increase of the electromagnetic field, the average diameter decreases from 52 to $40 \mu \mathrm{m}$ and the average shape factor of the particles increases from 0.52 to 0.69 .

The energy density of the magnetic field represents pressure acting orthogonally to the magnetic field and toward the center of the melt. So, the resulting pressure difference imposed on the melt causes forced convection as soon as the action of the electromagnetic force is exerted. In the conventional sand cast, the molten metal begins to solidify as it comes in contact with the mold wall. However, in the case of electromagnetic stirring, many initial solidified nuclei forming on the wall of the mold in a heterogeneous nucle-
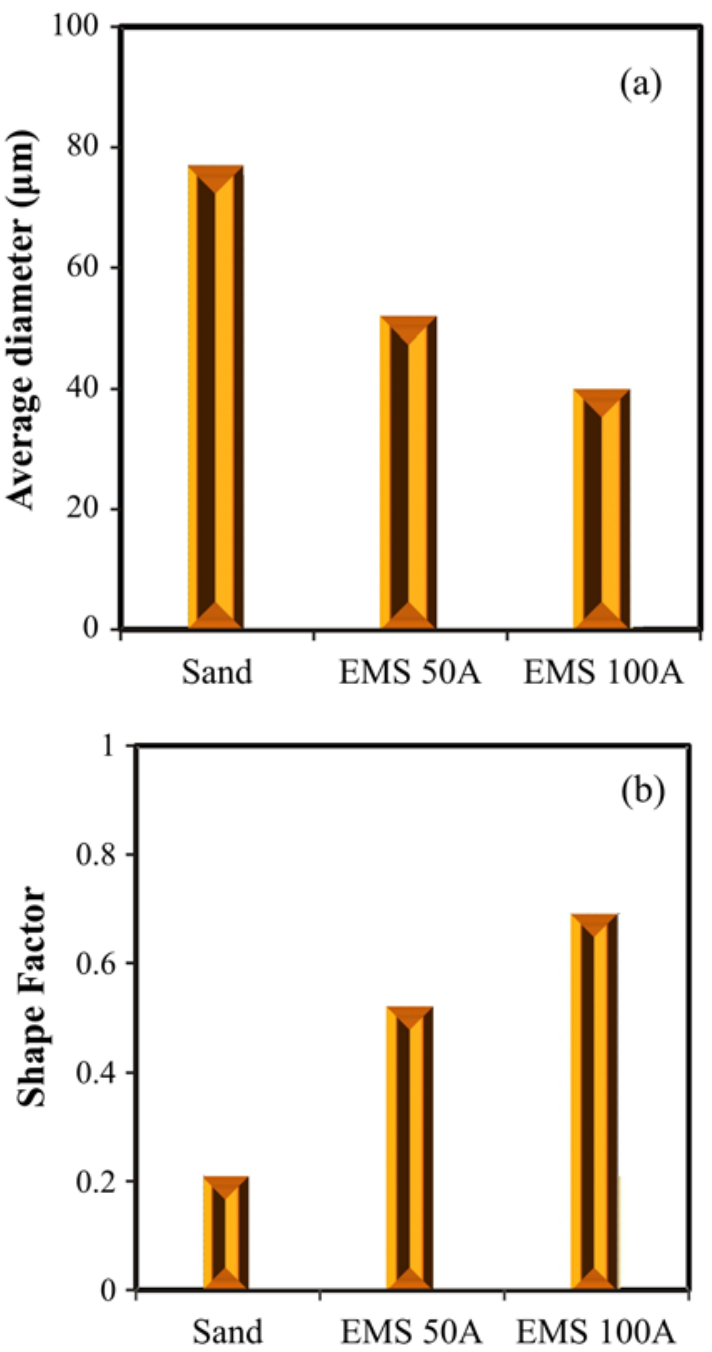

Fig. 6. Effect of various electromagnetic currents on average diameter (a) and shape factor (b) of primary phase in semisolid A356 Al alloy slurry. 

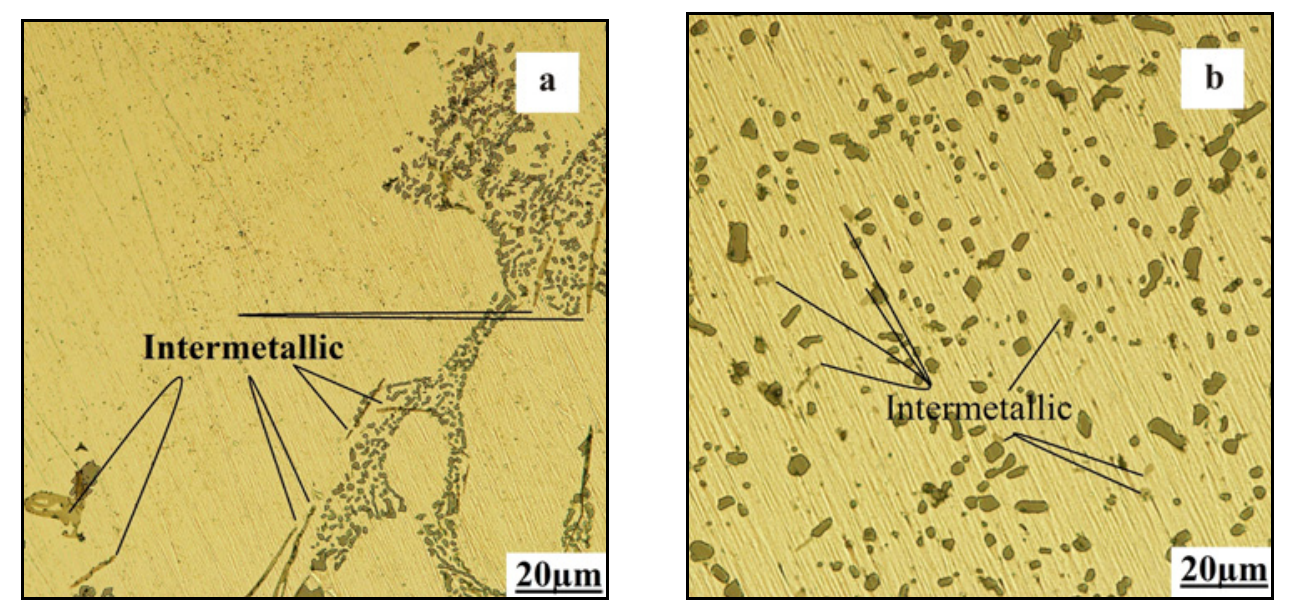

Fig. 7. The microstructure of the $\mathrm{Al}$ reinforced with $2.3 \%$ nano-TiC particulates: (a) conventional liquid sand cast and (b) compocast $(100 \mathrm{~A})$.
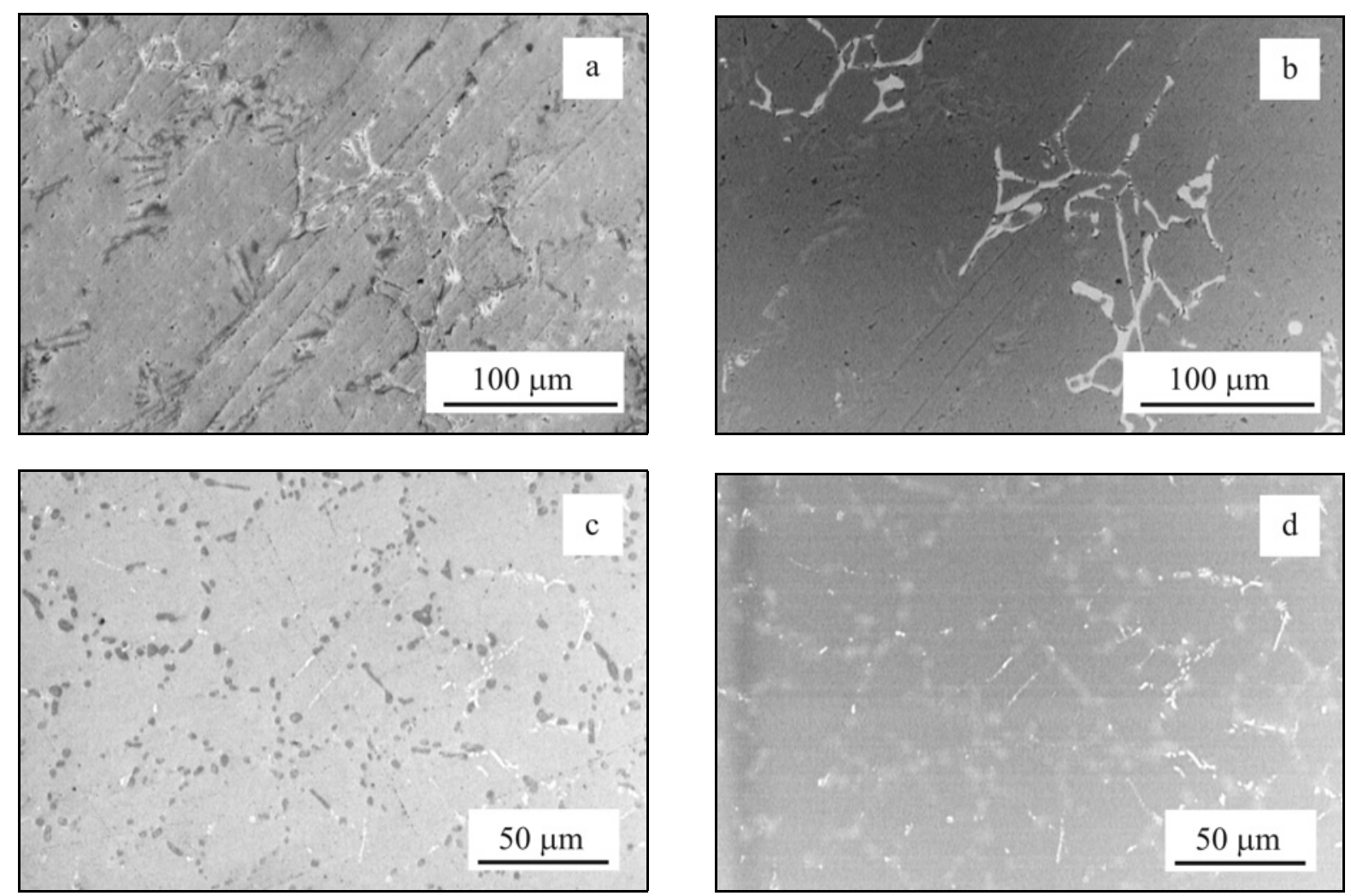

Fig. 8. SEM of Al reinforced with $2.3 \%$ nano-TiC particulates: (a) SE, (b) BSE in the conventional liquid sand cast, (c) $\mathrm{SE}$, and (d) BSE in compocast (100 A).

ation pattern are easily broken off by vibrating forces and would be transported into the entire liquid metal. Thus, the number of nuclei in the melt is increased. During growth, if the melt is held out of an electromagnetic field, the primary dendrites grow up, and the secondary dendritic arms develop unrestrainedly, so the solid advances in the form of dendrites to form the coarse grains. In contrast, in the case of electromagnetic stirring, application of an EMS to melt will produce a forced convection. The secondary dendritic arms may detach from the primary dendrites, and the melt rushes to the top of the primary dendrites at the solid/liquid interface so that the primary dendrites can be fractured. Therefore, the fractured tips of the columnar dendrites or the broken-off dendrite branches promote the formation of an equiaxed structure with fine grains, and the broken pieces can be carried by the forced convection into the bulk melt, 
Table 1. The hardness of the $\mathrm{Al}$ matrix nanocomposite reinforced with $2.3 \%$ nano-TiC produced by a variety of electromagnetic fields

\begin{tabular}{cccc}
\hline $\mathrm{Al}$ & Sand & EMS 50 A & EMS 100 A \\
\hline Hardness (BHN) & 71 & 76 & 80 \\
\hline
\end{tabular}

acting as nuclei. Here it should be pointed out that the Joule heat induced by the induction current also affects the solidification process. If the induction current passes through the melt, the most Joule heat will be generated at the solid/liquid interface of the dendrite root because the difference in electrical resistivity is the largest, which will spheroidize the dendrites and change their shape into globular.

In aluminum-silicon alloy, the secondary dendrite arm spacing (SDAS), the shape and distribution of eutectic silicon particles and secondary phases all control the tensile properties of pore-free castings. The presence of Fe-rich secondary phases affects the mechanical properties of Al-Si alloy, in particular, the ductility of the alloy. The amount and number of Fe-rich intermetallics strictly depend on the magnesium content and solidification process.

Figure 7 shows the microstructure of the $\mathrm{Al}$ matrix reinforced with $2.3 \%$ nano-TiC particulates. The good combination of strength and elongation of compocast samples is mainly derived from the extremely low porosity, fine size and equiaxed morphology of the Fe-containing intermetallic compounds, and perhaps more importantly, the fine and uniform microstructure throughout the entire sample. This is a direct result of the unique solidification behavior of Al-alloys during the compocast process. The Al alloy which is used in this study contains 0.3 wt.\% Fe. SEM micrographs (BSE) confirm the presence of Fe-containing intermetallic compound, which has a fine particle size and a compact morphology (Fig. 8d). This is very different from the Fe-containing intermetallic compound observed in the sand cast samples which usually appear as large plates or needles (Fig. 8b). Fine and spherical Fe-containing intermetallic particles are less harmful to mechanical properties, particularly ductility.

The most important factor in the fabrication of MMCs is the uniform dispersion of the reinforcements. Figure 9 represents typical SEM images of this composite in conventional liquid sand cast and EMS with $I=100$ A. Figure $9 \mathrm{~b}$ shows the uniform distribution of $\mathrm{TiC}$ particles through the matrix alloy. It is assumed that electromagnetic field improves the wetting kinetics in the liquid aluminum which results in uniform distribution of $\mathrm{TiC}$ particles. It is believed that strong mechanical bonding made between $\mathrm{Al}$ and $\mathrm{TiC}$ parti-
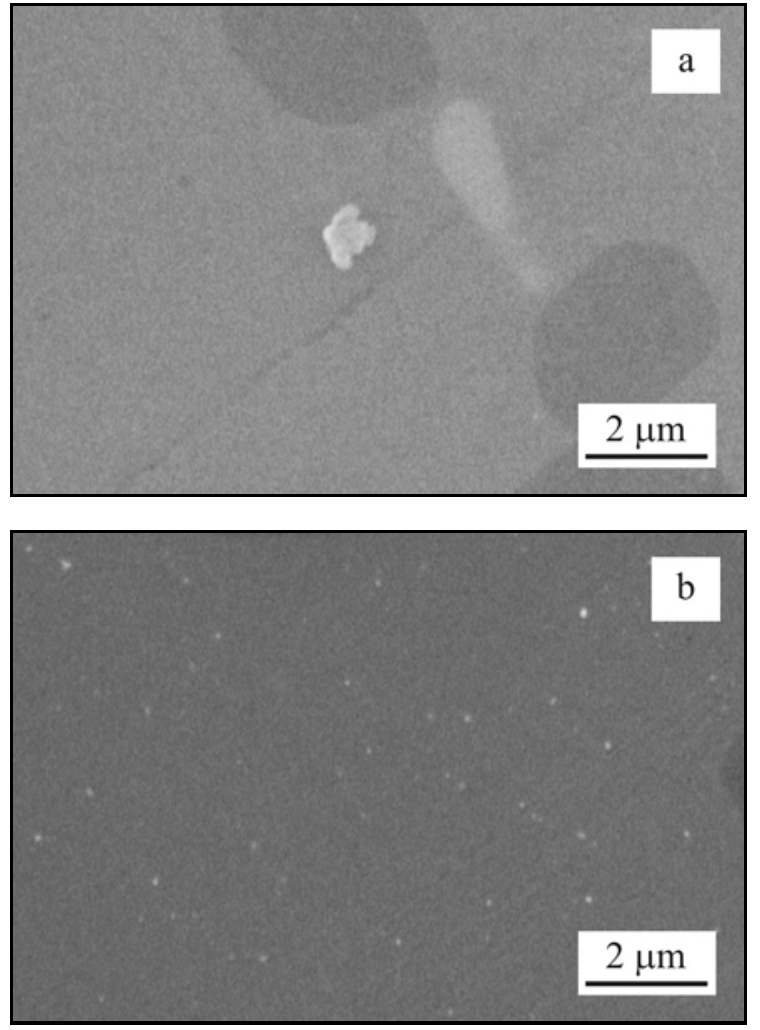

Fig. 9. The microstructure of the $\mathrm{Al}$ reinforced with $2.3 \%$ nano-TiC particulates: (a) conventional liquid sand cast and (b) compocast.

cles combined with EMS process help to disperse them more uniformly in the liquid.

Table 1 shows the hardness of the EMS Al matrix composite reinforced with $2.3 \%$ nano-TiC produced by a variety of electromagnetic fields. The highest value of hardness is obtained by addition of $2.3 \%$ TiC nanoparticles and using an electromagnetic current of $I=100 \mathrm{~A}$ which is attributed to a finer dendritic microstructure and uniform distribution of $\mathrm{TiC}$ nanoparticles. The hardness of this alloy is enhanced by precipitation of $\mathrm{Mg}_{2} \mathrm{Si}$ in the supersaturated $\mathrm{Al}$ solid solution.

Figure 10 shows the weight loss as a function of sliding distance at an applied load of $20 \mathrm{~N}$. It is noted that the weight loss of the EMS composite is less than that of conventional cast composite. The weight loss increases with increase in sliding distance and has a declining trend with increasing the electromagnetic field. This result is consistent with the rule that in general, materials with higher hardness have better wear and abrasive resistance. It is known that the wear loss is inversely proportional to the hardness of alloys $[10,52]$. In the case of conventional cast composite, the depth of penetration is governed by the hardness of the specimen surface and applied load [53]. But, in the case of EMS composite, the depth of penetra- 


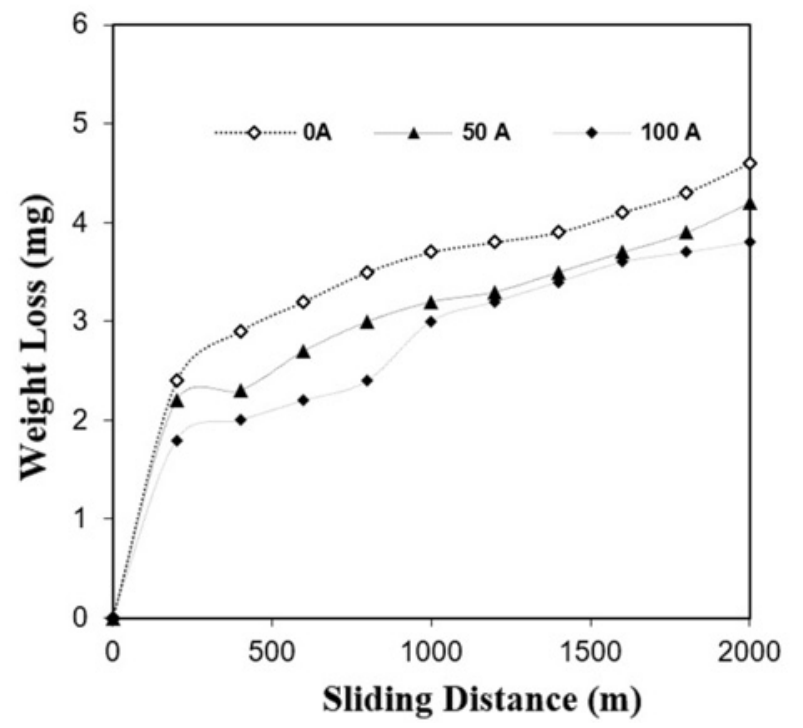

Fig. 10. The weight loss as a function of sliding distance.

tion of the harder asperities of hardened steel disc is primarily governed by the protruded hard and fine ceramic reinforcements that disperse in the overall matrix and also fine dendrites. Thus, the major portion of the applied load is carried by particles. The role of the reinforcement particles is to support the contact stresses preventing high plastic deformations and abrasion between contact surfaces and hence reduce the amount of worn material [54].

The wear surface of the conventional cast composite under the applied load of $20 \mathrm{~N}$ is depicted in Fig. 11a. The conventional cast matrix alloy is much softer than the counter body material and during sliding counter body penetrates into the matrix alloy producing deep grooves and causing extensive plastic deformation of the surface, which results in great material loss and significant wear rate. The worn surfaces also contain the evidence of adhesive wear in the form of adhesive pits. On the other side, the large scale of the matrix alloy is transferred to the counter body. The flow of materials along the sliding direction, generation of cavities due to delamination of surface materials and tearing of surface material is also noted in this figure. Worn surface EMS (100 A) composite at an applied load of $20 \mathrm{~N}$ is shown in Fig. 11b. It indicates the formation of continuous wear grooves, relatively smooth mechanically mixed layers, and some damaged regions. However, the degree of cracks formation on the wear surface is not much. The wear surface is characterized by the formation of parallel lips along the continuous groove marking. The sliding surface features a transfer layer of compacted wear which reaches a critical thickness before being detached leading to the formation of wear debris. The load, sliding speed determine the extent of this transfer layer,
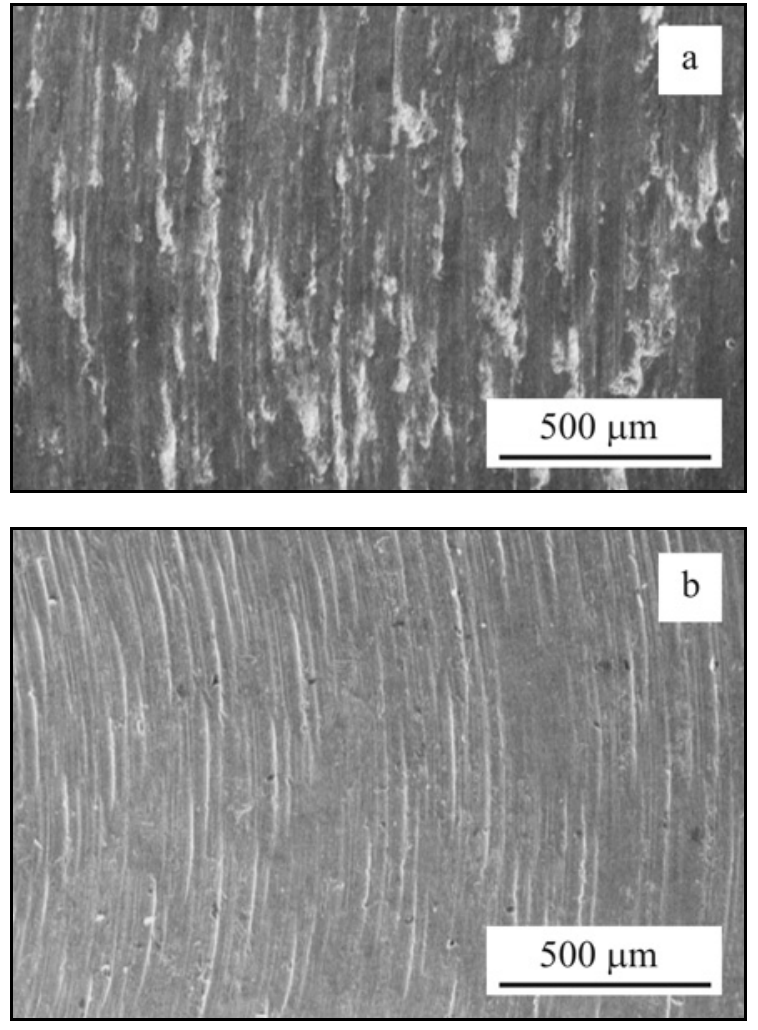

Fig. 11. SEM images of the wear surface of $\mathrm{Al}$ reinforced with $2.3 \%$ nano-TiC particulates: (a) conventional liquid sand cast and (b) compocast.

which increases with increasing load due to the higher frictional heating and a higher level of compaction. Morphology of wear debris collected during the tests is also shown in Fig. 12. Debris formed during the wear mostly from the pin material. Sharp edge, platelike particles are dominant. Among the wear debris of the composite at higher specific loads. plastic flow of material could be observed on the surface of these plate-like particles. Therefore, plate-like wear debris with sharp edges prevail at higher specific load, which are typical for adhesive wear. Moreover, the presence of the rod-like particles is an indication of severe wear.

\section{Conclusions}

This work shows the usefulness of an intelligent way to predict the performance of Al matrix composites using particle swarm optimization. The optimum parameters are used in the experimental procedure. EMS plays an important role in the formation of nondendritic primary $\alpha$-Al particles in $\mathrm{Al}$ alloy slurry. It can be seen that the increase in EMS current causes smaller and rounder primary $\alpha$-Al particles. The maximum sphericity and medium mean diameter of the globules are obtained by $I=100 \mathrm{~A}$. 

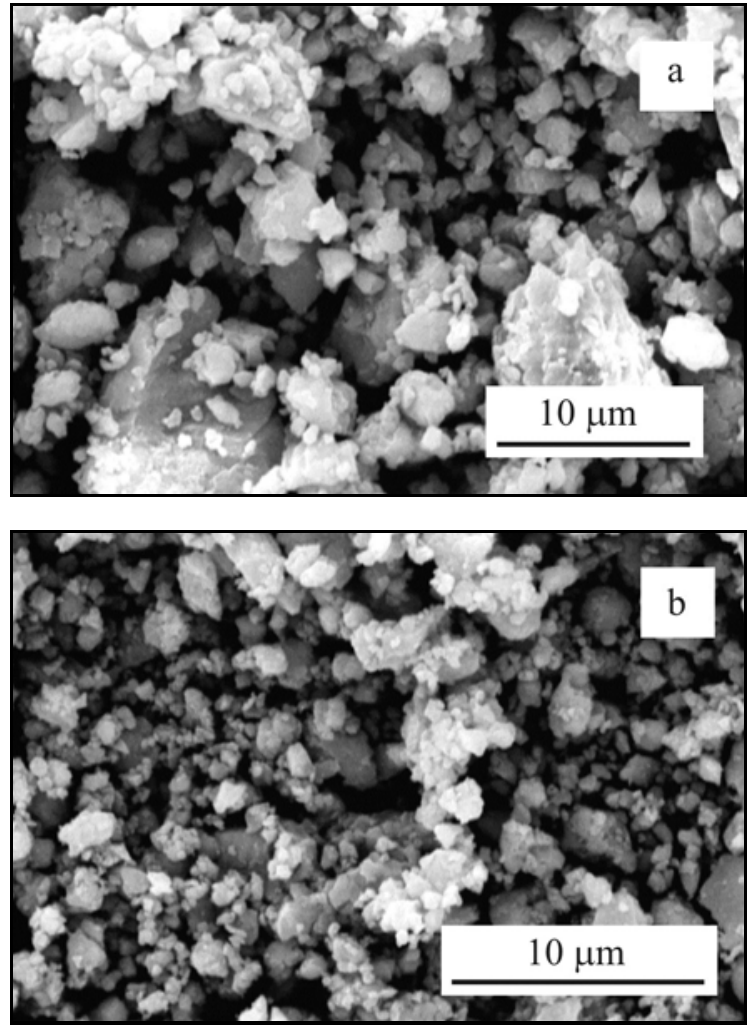

Fig. 12. Morphology of wear debris of $\mathrm{Al}$ reinforced with $2.3 \%$ nano-TiC particulates: (a) conventional liquid sand cast and (b) compocast.

A comparative study on abrasive wear behavior of nano-TiC reinforced aluminum metal matrix composite has been carried out in the present investigation. The mass loss of the pin was used to study the effect of $\mathrm{TiC}$ addition on the wear resistance of the composite materials. The TiC particulates increase the bulk hardness of the base Al alloy. In general, EMS composites offer superior wear as compared to the sand cast irrespective of applied load and sliding speed. The wear properties of EMS compocast samples benefit from the refinement of the primary $\alpha$-Al phase and uniform distribution of eutectic Si particles. The reason for lower wear rate in EMS composites can be attributed to their high hardness as compared to the conventional cast, resulting in a lower real area of contact and therefore lower wear rate. One of the common features observed on the worn surfaces of both base conventional cast and EMS composite is the formation of grooves and ridges running parallel to the sliding direction.

\section{Acknowledgement}

This Research work was supported by Najafabad branch, Islamic Azad University under grant of research project "Optimization of mechanical properties and microstructure of nano composite $\mathrm{Al}-\mathrm{TiC}$ in casting process".

\section{References}

[1] Mao, F., Yan, G., Xuan, Z., Cao, Z., Wang, T.: Journal of Alloys and Compounds, 650, 2015, p. 896. doi:10.1016/i.jallcom.2015.06.266

[2] Mazahery, A., Shabani, M. O.: Journal of Composite Materials, 48, 2014, p. 1927. doi:10.1177/0021998313492357

[3] Bahmani, A., Eisaabadi, G. B., Davami, P., Varahram, N., Shabani, M. O.: Russian Journal of Non-Ferrous Metals, 55, 2014, p. 365. doi:10.3103/S106782121404004X

[4] Mazahery, A., Shabani, M. O., Alizadeh, M., Tofigh, A. A.: Journal of Composite Materials, 47, 2012, p. 1765. doi:10.1177/0021998312451298

[5] Shabani, M., Mazahery, A., Rahimipour, M., Tofigh, A., Razavi, M.: Kovove Mater., 50, 2012, p. 25. doi:10.4149/km.2012.1.25

[6] Shabani, M. O., Mazahery, A., Bahmani, A., Davami, P., Varahram, N.: Kovove Mater., 49, 2011, p. 253. doi:10.4149/km.2011.4.253

[7] Bahmani, A., Hatami, N., Varahram, N., Davami, P., Shabani, M. O.: International Journal of Advanced Manufacturing Technology, 64, 2013, p. 1313. doi:10.1007/s00170-012-4102-7

[8] Shabani, M. O., Mazahery, A.: Russian Journal of Non-Ferrous Metals, 55, 2014, p. 436. doi:10.3103/S1067821214050150

[9] Mazahery, A., Shabani, M. O.: JOM, 66, 2014, p. 726. doi:10.1007/s11837-014-0968-1

[10] Vencl, A., Bobić, I., Arostegui, S., Bobić, B., Marinković, A., Babić, M.: Journal of Alloys and Compounds, 506, 2010, p. 631. doi:10.1016/i.jallcom.2010.07.028

[11] Mazahery, A., Shabani, M. O., Rahimipour, M. R., Razavi, M.: Journal of Composite Materials, 46, 2012, p. 2647. doi:10.1177/0021998311431352

[12] Razavi, M., Rajabi-Zamani, A. H., Rahimipour, M. R., Kaboli, R., Shabani, M. O., Yazdani-Rad, R.: Ceramics International, 37, 2011, p. 443. doi:10.1016/j.ceramint.2010.09.013

[13] Shabani, M. O., Mazahery, A.: Transactions of the Indian Institute of Metals, 66, 2013, p. 65. doi:10.1007/s12666-012-0227-5

[14] Baghani, A., Bahmani, A., Davami, P., Varahram, N., Shabani, M. O.: Defect and Diffusion Forum, 344, 2013, p. 43. doi:10.4028/www.scientific.net/DDF.344.43

[15] Faraji, A. H., Bahmani, A., Goodarzi, M., Seyedein, S. H., Shabani, M. O.: Journal of Central South University, 21, 2014, p. 20. doi:10.1007/s11771-014-1910-y

[16] Mazahery, A., Shabani, M. O.: Ceramics International, 38, 2012, p. 1887. doi:10.1016/j.ceramint.2011.10.016

[17] Baghani, A., Bahmani, A., Davami, P., Varahram, N., Shabani, M. O.: Proceedings of the Institution of Mechanical Engineers. Part L: Journal of Materials: Design and Applications, 229, 2015, p. 106. doi:10.1177/1464420713500182

[18] Shabani, M. O., Mazahery, A.: Engineering with Computers, 30, 2012, p. 559. doi:10.1007/s00366-012-0299-1 
[19] Mazahery, A., Alizadeh, M., Shabani, M. O.: Transactions of the Indian Institute of Metals, 65, 2012, p. 393. doi:10.1007/s12666-012-0143-8

[20] Rahimipour, M. R., Tofigh, A. A., Mazahery, A., Shabani, M. O.: Tribology - Materials, Surfaces and Interfaces, 7, 2013, p. 129. doi:10.1179/1751584X13Y.0000000034

[21] Shabani, M. O., Mazahery, A.: Materiali in Tehnologije, 46, 2012, p. 613

[22] Lach, R., Haberko, K., Bućko, M. M., Grabowski, G.: Ceramics International, 41, 2015, p. 10488. doi:10.1016/j.ceramint.2015.04.136

[23] Mazahery, A., Shabani, M. O.: Tribology Transactions, 56, 2013, p. 342 . doi:10.1080/10402004.2012.752552

[24] Rahimipour, M. R., Tofigh, A. A., Shabani, M. O., Davami, P.: Tribology in Industry, 36, 2014, p. 220.

[25] Shabani, M. O., Mazahery, A.: Ceramics International, 39, 2013, p. 1351. doi:10.1016/j.ceramint.2012.07.073

[26] Chen, Q., Chen, G., Han, L., Hu, N., Han, F., Zhao, Z., Xia, X., Wan, Y.: Journal of Alloys and Compounds, 656, 2016, p. 67. doi:10.1016/j.jallcom.2015.09.135

[27] Lam, Y.-K., Tsang, P. W. M., Leung, C.-S.: Neural Computing and Applications, 22, 2013, p. 1349. doi:10.1007/s00521-012-0959-5

[28] Mazahery, A., Shabani, M. O.: Powder Technology, 245, 2013, p. 146. doi:10.1016/j.powtec.2013.04.035

[29] Rahimipour, M. R., Tofigh, A. A., Mazahery, A., Shabani, M. O.: Neural Computing and Applications, 24, 2014, p. 1531. doi:10.1007/s00521-013-1375-1

[30] Shabani, M. O., Mazahery, A.: Metallurgist, 56, 2012, p. 414. doi:10.1007/s11015-012-9591-y

[31] Tofigh, A. A., Shabani, M. O.: Ceramics International, 39, 2013, p. 7483. doi:10.1016/j.ceramint.2013.02.097

[32] Sudheer, C., Maheswaran, R., Panigrahi, B. K., Mathur, S.: Neural Computing and Applications, 24, 2014, p. 1381. doi:10.1007/s00521-013-1341-y

[33] Mazahery, A., Shabani, M. O.: Powder Technology, 249, 2013, p. 530. doi:10.1016/j.powtec.2013.08.005

[34] Shabani, M. O., Mazahery, A.: JOM, 65, 2013, p. 272. doi:10.1007/s11015-012-9591-y

[35] Mazahery, A., Shabani, M. O.: Kovove Mater., 51, 2013, p. 333. doi:10.4149/km-2013-6-333

[36] Li, B., Pan, Q., Yin, Z.: Journal of Alloys and Compounds, 584, 2014, p. 406. doi:10.1016/j.jallcom.2013.09.036

[37] Mazahery, A., Shabani, M. O.: Russian Metallurgy (Metally), 2011, 2011, p. 699. doi:10.1134/S0036029511070196
[38] Shabani, M. O., Alizadeh, M., Mazahery, A.: Fatigue and Fracture of Engineering Materials and Structures, 34, 2011, p. 1035.

doi:10.1111/j.1460-2695.2011.01592.x

[39] Tofigh, A. A., Rahimipour, M. R., Shabani, M. O., Alizadeh, M., Heydari, F., Mazahery, A., Razavi, M.: Journal of Manufacturing Processes, 15, 2013, p. 518. doi:10.1016/j.jmapro.2013.08.004

[40] Shabani, M., Alizadeh, M., Mazahery, A.: Fatigue \& Fracture of Engineering Materials \& Structures, 34, 2011, p. 1035. doi:10.1111/i.1460-2695.2011.01592.x

[41] Zeng, W., Chen, N.: Journal of Alloys and Compounds, 257, 1997, p. 266. doi:10.1016/S0925-8388(97)00032-7

[42] Mazahery, A., Shabani, M. O.: Metallurgical and Materials Transactions A: Physical Metallurgy and Materials Science, 43, 2012, p. 5279 . doi:10.1007/s11661-012-1339-6

[43] Shabani, M. O., Mazahery, A.: Indian Journal of Engineering and Materials Sciences, 19, 2012, p. 129

[44] Tofigh, A. A., Rahimipour, M. R., Shabani, M. O., Davami, P.: Journal of Composite Materials, 49, 2015, p. 1653. doi:10.1177/0021998314538871

[45] Rajabloo, T., Ghafarinazari, A., Seyed Faraji, L., Mozafari, M.: Journal of Alloys and Compounds, 607, 2014, p. 61. doi:10.1016/j.jallcom.2014.03.124

[46] Shabani, M. O., Rahimipour, M. R., Tofigh, A. A., Davami, P.: Neural Computing and Applications, 26, 2015, p. 899. doi:10.1007/s00521-014-1724-8

[47] Shamshirband, S., Malvandi, A., Karimipour, A., Goodarzi, M., Afrand, M., Petković, D., Dahari, M., Mahmoodian, N.: Powder Technology, 284, 2015, p. 336. doi:10.1016/j.powtec.2015.06.073

[48] Shabani, M. O., Mazahery, A.: JOM, 63, 2011, p. 132. doi:10.1007/s11837-011-0127-x

[49] Mazahery, A., Shabani, M. O., Alizadeh, M., Tofigh, A. A.: Journal of Composite Materials, 47, 2013, p. 1765. doi: $10.1177 / 0021998312451298$

[50] Shabani, M. O., Mazahery, A.: Powder Technology, 249, 2013, p. 77. doi:10.1016/j.powtec.2013.07.032

[51] Mazahery, A., Shabani, M. O., Elrefaei, A.: International Journal of Damage Mechanics, 23, 2014, p. 899. doi:10.1177/1056789513518951

[52] Tofigh, A. A., Rahimipour, M. R., Shabani, M. O., Davami, P.: Journal of Composite Materials, 49, 2014, p. 1653. doi:10.1177/0021998314538871

[53] Mazahery, A., Shabani, M.: Strength of Materials, 44, 2012, p. 686.

[54] Hutchings, I. M.: Powder Technology, 76, 1993, p. 3. doi:10.1016/0032-5910(93)80035-9 